\title{
ESTUDO DA POTENCIALIDADE TURÍTICA DO PARQUE NACIONAL DE SETE CIDADES - PIAUÍ
}

\author{
STUDY OF THE TOURIST POTENTIAL OF THE SETE \\ CIDADES NATIONAL PARK - PIAUI
}

\section{Ronaldo Oliveira Pereira Araujo \\ Graduando do Curso de Bacharelado em Turismo na Universidade Federal Delta do Parnaíba - UFDPar. E-mail: ronaldoaraujophb@hotmail.c om}

Nathalia da Silva Araujo Graduanda do Curso de Bacharelado em Turismo na Universidade Federal Delta do Parnaíba - UFDPar. E-mail: nathaliasilvaaraujo@yahoo.co m.br

Solano de Souza Braga

Professor do Curso de Bacharelado em Turismo na Universidade Federal Delta do Parnaíba - UFDPar. E-mail: solanobraga@yahoo.com.br

Sofia Araujo de Oliveira Professora do Curso de Bacharelado em Turismo na Universidade Federal Delta do Parnaíba - UFDPar. E-mail: sofiaoliveira@ufpi.edu.br

Waldemar Justo do Nascimento Neto Gestor do PARNA de Sete Cidades. E-mail: waldemar.neto@icmbio.gov. br

\section{Resumo}

O Ecoturismo é uma alternativa para apreciar a natureza, sendo um refúgio das atividades rotineiras dos grandes centros. Unidades de Conservação, como os Parques Nacionais, são áreas de proteção ambiental salvaguardadas de atividades impactantes à fauna e flora por atividades antrópicas, contribuindo para a preservação e conservação da biodiversidade dos biomas para as gerações futuras. Desta forma, como esses espaços são receptores de turistas, faz-se necessário uma estrutura para recebê-los, assim o principal objetivo do artigo é analisar a estrutura do Parque Nacional de Sete Cidades localizado no Piauí, a partir da análise SWOT. A metodologia empregada foi de cunho qualitativo, bibliográfico e pesquisa de campo. Assim sendo, pode-se concluir que o PARNA apresenta relevantes pontos fortes $\mathrm{e}$ oportunidades para se trabalhar o turismo, entretanto observam-se necessárias melhorias a serem aplicadas para que se tenha um melhor atendimento ao turista, além de investimentos em marketing atraindo, assim, mais visitantes ao PARNA.

Palavras-chave: PARNA de Sete Cidades; Análise SWOT, Unidade de Conservação.

\begin{abstract}
Ecotourism is an alternative to enjoying nature, being a refuge from the routine activities of large urban centers. Conservation Units, such as National Parks, are environmental protection areas safeguarded impacting fauna and flora by human activities, contributing to the preservation and conservation of biodiversity in biomes for future generations. In this way, as these places attract tourists, it is necessary a structure to receive them, so the main objective of the article is to analyze the structure of the Sete Cidades National Park located in Piauí, from the SWOT analysis. The methodology used was qualitative, bibliographic and field research. Therefore, it can be concluded that the National Park has relevant strengths and opportunities for working with tourism, however, there are necessary improvements to be applied in order to have a better service to tourists, in addition to investments in marketing, thus attracting more visitors to the Park.
\end{abstract}

Keywords: Sete Cidades National Park; SWOT Analysis, Conservation Unit. 


\section{INTRODUÇÃO}

O ecoturismo vem crescendo cada vez mais nas últimas décadas mediante a necessidade cada vez maior de fuga dos grandes centros urbanos, os quais possuem um ambiente estressante, fazendo com que as pessoas busquem um contato maior com a natureza para fugir do ritmo das cidades, criando uma relação mais estreita com ambientes naturais de forma mais consciente e sustentável.

Ruschmann (1997) indaga que muitas pessoas acabam por, de certa forma, fugir dos grandes centros urbanos devido à deterioração das condições de vida nesses lugares, fazendo com que esse número de pessoas acabe procurando nas férias ou em fins de semana os ambientes naturais. Por isso, embora as Unidades de Conservação (UCs) em geral tenham sido criadas com o objetivo de salvaguardar os recursos naturais, elas acabam por ser usadas pelo turismo, proporcionando a relação homem-natureza.

Nesse sentido, o interesse por este estudo advém da temática ambiental trabalhada no curso de Bacharelado em Turismo ${ }^{1}$, que fez refletir sobre a prática do turismo em ambientes naturais e do modo que é operacionalizado. Nesse caminho, discentes desenvolvem capacidades e habilidades que lhes permitem questionar como a atividade do turismo vem sendo praticada, permitindo percepções e análises mais alinhadas com o desenvolvimento sustentável desses destinos e atrativos.

Dito isto, sabe-se que o Brasil é privilegiado com uma variedade de destinos ecológicos, possuindo seis biomas (Cerrado, Caatinga, Mata Atlântica, Pampa, Amazônia e Pantanal) (VARELLA \& NOVAIS, 2018). Devido à grande quantidade de recursos naturais e uma variedade de biomas dentro do território nacional, o Brasil é contemplado com vários tipos de ecossistemas, os quais abarcam diversas espécies de animais e vegetais, o que proporciona, assim, a sua grande biodiversidade.

Os autores Bohrer e Dutra (2009), afirmam que isso não advém apenas da grande extensão territorial do país, mas também por estar localizado na zona tropical, com grandes áreas de floresta tropical úmida, bioma que abriga uma proporção extremamente grande do total de espécies que ocorrem no planeta. Contudo, dentro de cada bioma brasileiro, atuam as Unidades de Conservação, as quais têm como objetivo primordial a

\footnotetext{
${ }^{1}$ Da Universidade Federal do Delta do Parnaíba (UFDpar), Campus Ministro Reis Velloso (CMRV), no qual somos discentes regularmente matriculados no oitavo período. Desse modo, disciplinas como Educação Ambiental e Desenvolvimento Sustentável, Biodiversidade Brasileira, Ecoturismo e monitoria de Educação Ambiental contribuíram para uma formação mais crítica com relação à prática do turismo em ambientes naturais.
} 
conservação desses espaços, bem como da diversidade biológica dos ecossistemas, de forma que se preserve todo o patrimônio biológico e natural existente nessas áreas (BRASIL, 2000).

Diante disto, caracterizado como UC de proteção integral, o Parque Nacional (PARNA) de Sete Cidades surgiu a partir do Decreto Federal n ${ }^{\circ} 50.744$, de 8 de junho de 1961 e conta uma área de 6.303,64 hectares. Localizado no Nordeste do estado do Piauí, entre os municípios de Piracuruca e Brasileira, o PARNA tem a finalidade de preservar a biodiversidade e a cultura presentes no local, permitindo apenas atividades controladas, planejadas e sustentáveis.

Dessa forma, o destino possibilita a visitação turística, promovendo o turismo científico, ecoturismo e turismo de aventura, devido à grande diversidade de ecossistema presente na área, bem como a possibilidade de realização de trilhas, a presença de cachoeira e de sítios arqueológicos com pinturas rupestres dos índios tabajaras, cariris e os Tremembé os quais residiam no local há muitos anos.

Nessa perspectiva, o PARNA possui grande potencial de atrativos turísticos para promover a prática da atividade turística dentro do seu espaço. Posto isto, a presente pesquisa pode contribuir para uma melhor gestão das atividades turísticas realizadas no PARNA, através de um olhar mais crítico, além de uma melhor visão acerca do turismo presente em áreas naturais protegidas. Mais ainda, o Parque Nacional de Sete Cidades trata-se de uma Unidade de Conservação (UC) de Proteção Integral, fato que proíbe a presença de populações humanas residindo nessas áreas, tornando necessária maior atenção sobre a atuação do turismo nesses locais.

Ademais, devido à inexistência de trabalhos científicos referentes à aplicação da análise SWOT associada à atividade turística no Parque Nacional de Sete Cidades, este estudo busca contribuir e servir como ferramenta para futuras pesquisas relacionadas a essa UC, mais precisamente na área do turismo. Diante do exposto, o presente artigo tem como objetivo compreender o modo como o turismo é operacionalizado no PARNA e analisar o local através de uma análise SWOT, observando, como objetivos específicos, as suas Strengths (Forças), Weaknesses (Fraquezas), Opportunities (Oportunidades) e Threats (Ameaças) decorrentes do turismo na área, para, a partir disso, atingir o objetivo geral e promover melhorias para fomentar o turismo com base em princípios sustentáveis e neutralizar os pontos negativos. 


\title{
UNIDADES DE CONSERVAÇÃO (UC)
}

Unidade de conservação, de acordo com o proposto pelo Sistema Nacional de Unidades de Conservação da Natureza (SNUC), é definida como:

\begin{abstract}
Espaço territorial e seus recursos ambientais, incluindo as águas jurisdicionais, com características naturais relevantes, legalmente instituído pelo Poder Público, com objetivos de conservação e limites definidos, sob regime especial de administração, ao qual se aplicam garantias adequadas de proteção (SNUC, 2000, p.5).
\end{abstract}

As UCs seguem a definição por trás das áreas naturais protegidas que, para Diegues (1997, p. 85), têm como objetivo principal "preservar espaços com atributos ecológicos importantes". A criação das UC, pois, surge com a finalidade de salvaguardar os recursos naturais de forma que proteja a diversidade biológica presente nos biomas nacionais, nos ecossistemas e nos mais variados habitats, tanto os de terra firma, como os presentes nas águas, a fim de proteger o patrimônio natural (BRASIL, 2000). Essa concepção, de áreas naturais protegidas surgiu no século XX nos Estados Unidos com a intenção de proteger a "a vida selvagem (wilderness) ameaçada, segundo seus idealizadores, pela civilização urbano-industrial, destruidora da natureza" (DIEGUES, 1997, p. 86).

Tal ideia surgiu com a finalidade de preservar áreas naturais em seu estado primitivo, podendo, assim, serem domesticadas pelo homem. Nesse contexto, obter-seiam áreas naturais protegidas, além de apenas espaços físicos, fator que estreitaria mais ainda a relação homem-natureza. Nesse contexto, o SNUC foi instituído pela Lei número 9.985, de 18 de julho de 2000, decretada pelo Congresso Nacional, a qual estabelece critérios e normas para a criação, implantação e gestão das UC, como consta no seu artigo $1^{\circ}$. Tendo, pois, isto, sua criação resultou em uma significativa ascensão na elaboração de um modelo de sistema efetivo de áreas protegidas no país.

O mesmo, ainda conforme a Lei 9.985/2000, será gerido pelos órgãos: consultivo e deliberativo, isto é, o Conselho Nacional do Meio Ambiente (CONAMA); órgão central, como o Ministério do Meio Ambiente (MMA); e, por fim, os órgãos executores, como o Instituto Chico Mendes de Conservação da Biodiversidade (ICMBio) e o Instituto Brasileiro do meio Ambiente (IBAMA); a fim de exercer comando e poder de administração desses espaços territoriais (as UC).

As UCs podem ser divididas em duas categorias propostas pelo SNUC. Nesse aspecto, têm-se as unidades de conservação de proteção integral e as de uso sustentável, sendo que cada uma se subdivide em diversas tipologias. Dessa forma, as UCs de proteção 
integral têm como objetivo fazer a manutenção dos ecossistemas, visando à sua preservação, admitindo apenas o uso indireto dos seus atributos naturais. Dentro dessas unidades, enquadram-se como tipologias: estação ecológica, reserva biológica, parque nacional e monumento natural e suas respectivas definições.

As UCs de uso sustentável, por sua vez, têm como objetivo explorar o meio natural e seus recursos ambientais renováveis de forma sustentável, socialmente justa e economicamente viável. Nesse tipo de área protegida, estão enquadradas as categorias: área de proteção ambiental (APA), área de relevante interesse ecológico, floresta nacional (FLONA), Reserva Extrativista (RESEX), reserva de fauna, reserva de desenvolvimento sustentável e reserva particular do patrimônio natural e suas respectivas definições.

Nesse contexto, no Brasil existem 312 UC geridas pelo ICMBio e, dentre elas, 73 são PARNAs, os quais se encontram distribuídos dentro dos seis biomas brasileiros (Amazônia, Cerrado, Mata Atlântica, Pampa, Pantanal e Marinho). Dito isto, esses PARNAs somam 346 mil quilômetros quadrados de áreas protegidas, mas apenas 26 oferecem estrutura para visitação (GAUTHIER et al., 2014). Sendo assim, dentro do proposto, pode-se afirmar que o Parque Nacional de Sete Cidades está enquadrado dentro da categoria de UC de proteção integral, visto que não é permitido dentro da área qualquer atividade de exploração como o extrativismo, agricultura ou moradia no local.

Apesar de o PARNA não ter sido criado para e pelo turismo, tendo enfoque de proteção ambiental, são desenvolvidas atividades turísticas que impactam positivamente a economia do entorno. Complementando essa visão, Silveira (2014) afirma que espaço turístico é, em outras palavras, aquele cuja criação se deu para e/ou pelo turismo e apresenta uma dimensão real e imaginária, podendo ser mapeado e constitui alvo de ações de empresas locais ou de fora e dos planejadores e promotores territoriais públicos e privados.

Dessa forma, além de estar enquadrada na categoria de UC, o PARNA também pode ser caracterizado como um sítio turístico, definido por Silveira (2014, p. 32) como "um lugar de visita e/ou passagem, e não de estadia de turistas; ou seja, por onde o turista passa de visita, mas não permanece, até mesmo porque não tem a função de hospedagem para turistas". Desse modo, pode ser constituído como atrativo turístico de acordo com o SEBRAE.

Os atrativos turísticos exercem papel fundamental para o desenvolvimento do turismo receptivo, uma vez que compõem a oferta turística diferencial de uma 
localidade, ou seja, são os principais responsáveis pela atratividade das regiões turísticas, que geram os fluxos turísticos. A qualidade da oferta desses atrativos impacta diretamente no posicionamento do destino no mercado turístico. (SEBRAE, 2017, p. 7)

Como um atrativo ofertado na região, de característica natural, o PARNA, juntamente com as suas "cidades", suas especificidades e características peculiares, as quais o fazem ser um local bastante diferenciado e que abarca um forte potencial natural e turístico; possui sob gestão órgãos executores na categoria de instituições, os quais são responsáveis pelo planejamento e desenvolvimento do local, como um espaço natural e turístico. Tais órgãos têm como objetivo subsidiar as propostas de criação, bem como administrar as UC federais, estaduais e municipais, dentro de suas respectivas esferas de atuação (BRASIL, 2007).

\section{CARACTERIZAÇÃO DA ÁREA}

O PARNA de Sete cidades é uma das três UC de conservação dessas categorias existentes no estado do Piauí, criado em 8 de junho de 1961 pelo Decreto Federal de 50.744. Localizado, na cidade de Piracuruca, na BR 222, km 6 (Figura 1). É visitado o ano todo devido à sua beleza natural, suas formações geomorfológicas as quais são diferenciadas por conterem com formas peculiares que podem ser visualizadas como representativas de elementos como elefante, cachorro, casco de tartaruga, ademais da cabeça o imperador D. Pedro I, entre outros. A visitação no parque oscilou entre a média de 18 a 20 mil visitantes por ano entre 2018 e 2019. O PARNA possui, dentre as suas estruturas físicas, um hotel com 12 (doze) suítes e restaurante que estão temporariamente desativados, dois auditórios, lanchonete, centro de visitantes e estruturas administrativas.

Inicialmente, com a criação do PARNA, este era gerido pelo Instituto Brasileiro do meio Ambiente (IBAMA), o qual era responsável pela fiscalização das atividades realizadas na área, sendo substituído logo depois por outro órgão executor, o Instituto Chico Mendes de Conservação da Biodiversidade (ICMBio), o qual exerce comando e poder de administração desses espaços territoriais. 
Figura 1: Localização do PARNA de Sete Cidade.

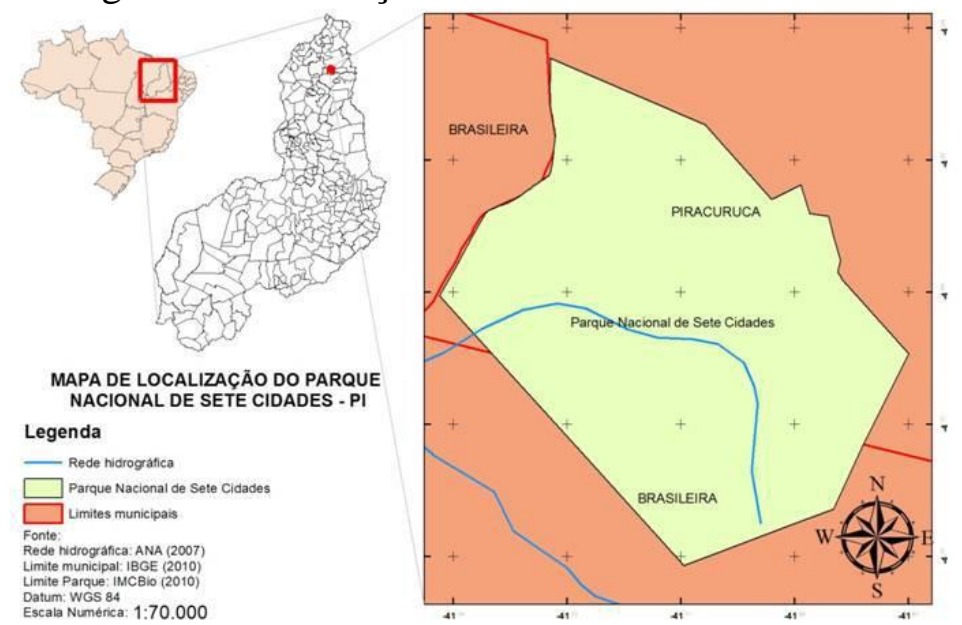

Fonte: Souza \& Pereira, 2019.

Na região compreendida pelo PARNA, é encontrado, portanto, a transição de dois biomas. Dessa forma, Walter (1986), apud Coutinho (2005), considera como bioma, uma área do espaço geográfico que possui dimensões superiores até um milhão de quilômetros quadrados, representada por um tipo homogêneo de ambiente. Nesse aspecto, os biomas presentes, os quais estão relacionados em significativo contato são o cerrado e a caatinga.

Com efeito, faz-se mais presente dentro do PARNA, espécies típicas do cerrado, em se falando de vegetação, tais como espécies como murici (Byrsonima crassifólia), lixeira (Curatella americana), bacuri (Platonia insignis), pequi (Caryocar brasiliense) e pau-terra (Qualea parviflora), avistadas com facilidade. Nas manchas de caatinga encontram-se juazeiros (Ziziphus joazeiro), aroeiras (Schinus terebinthifolius) e cactos, como o xique-xique (Pilosocereus Gounellei) (Figura 2), e a coroa-de-frade (Melocactus zehntneri) (ICMBio, 2020).

Figura 2: Xique-xique (Pilosocereus Gounellei).

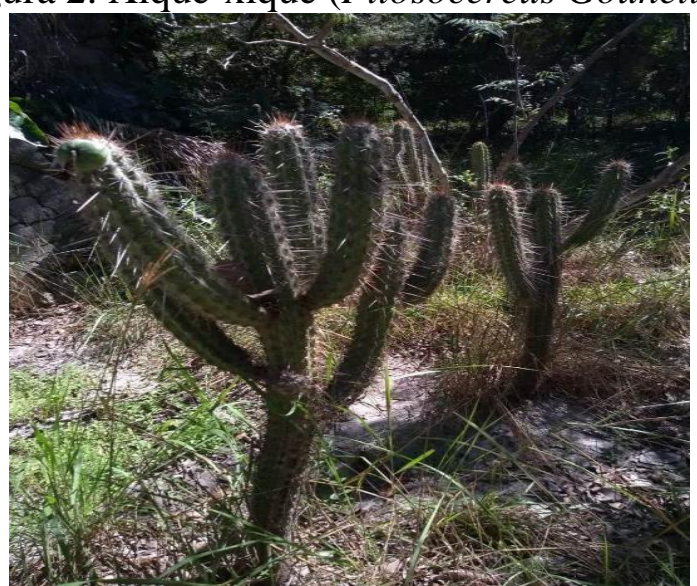

Fonte: Pesquisa Direta, 2018.

O PARNA é caracterizado pela presença notável de diversas formações 
geológicas, as quais são consideradas e denominadas "cidades", os blocos de rochas, devido ao fato de lembrarem formatos de pessoas, animais, objetos e ruínas de número 1 a 7 (Figura 3). Tal denominação é devido a um jornalista cearense que visitou o PARNA em 1886 que ao visualizar as formações rochosas assemelhou a uma cidade que se petrificou e fez uma publicação sobre o PARNA, caracterizando as "cidades" encontradas por ele.

O parque possui uma área de 6.221 hectares, com alguns animais de ambos os biomas, tais como o mocó (Kerodon rupestris), que de acordo com o que consta no Plano de Manejo de Sete Cidades (1979, p. 28) é o "roedor mais tipicamente característico das áreas rupestres da caatinga"; cutia (Dasyprocta punctata), jacu (Penelope ochrogaster), veado campeiro (Ozotocerus bezoarticus), suçuarana (Felis concolor), jaguatirica (Leopardus pardalis), 22 espécies de cobras catalogadas e 52 espécies de pássaros, e algumas plantas medicinais como a copaíba (Copaifera langsdorffii).

Figura 3: Mapa das Sete Cidades.

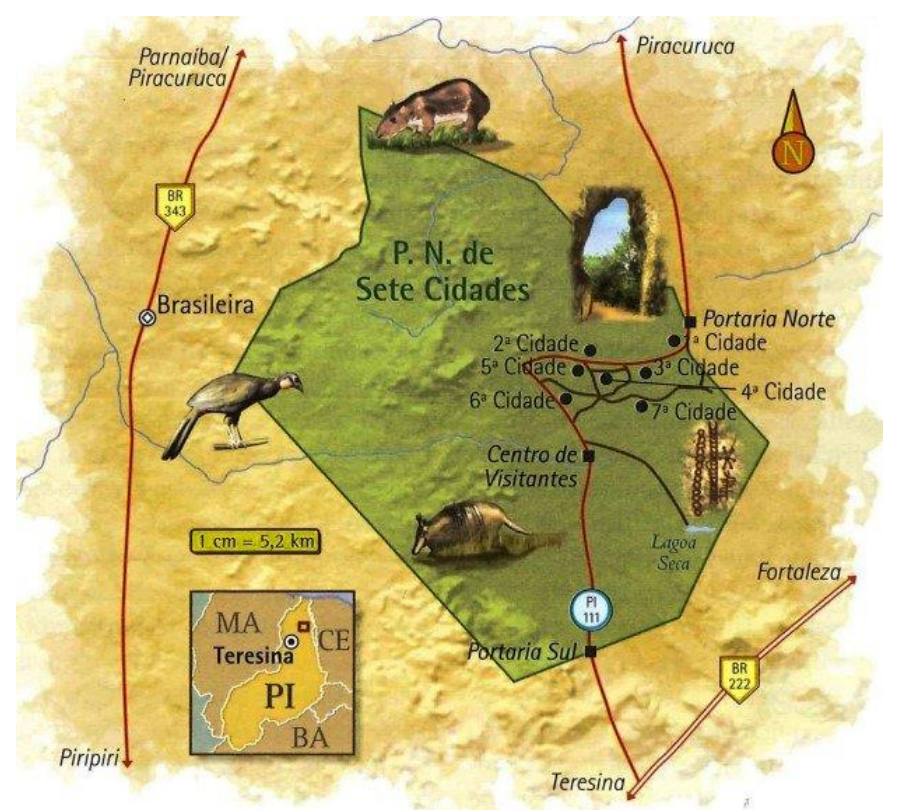

Fonte: Fonte: https://www.bahia.ws/parque-nacional-de-sete-cidades-piaui/

Cabe destacar a variedade e beleza das formações geomorfológicas presentes no PARNA, como em formatos de elefante, cachorro, tartaruga, o imperador Dom Pedro I, mapas de países, etc. É interessante mencionar, ainda, pinturas rupestres como aspectos histórico-culturais, além de cachoeira e piscinas naturais, as quais podem ser visitadas durante o período chuvoso. A seguir serão descritas as "Cidades" com base na experiência de campo. Todas as cidades foram visitadas e as informações apresentadas se baseiam na 
interpretação realizada pelos condutores locais, observações dos pesquisadores e dados secundários.

\section{As Sete Cidades}

A Primeira Cidade é conhecida como "Pedra do Canhão" por conter formações geológicas que se assemelham ao instrumento utilizado para guerra, podendo ser também comparadas a troncos de árvores petrificados devido ao seu formato, no entanto, trata-se apenas de uma formação na rocha ocorrida ao longo do tempo, contendo substâncias químicas como o ferro. Próxima a essa Cidade está uma cachoeira sazonal (FIGURA 4) que atraí muito visitantes ao PARNA durante os períodos chuvosos (de janeiro a maio).

A Segunda Cidade é o local no qual se encontra o ponto mais alto do PARNA, o então denominado "Arco do Triunfo" (FIGURA 3), uma homenagem à França, visto que dois franceses estiveram ali no PARNA e também devido à sua forma que se assemelha ao arco francês. O local pode ser chamado ainda de "Portal dos Desejos", pelos moradores do local, que sentiam uma concentração de energia e, dessa forma, começaram a passar pelo arco e fazer um pedido, pois se acredita que ao passar, deve-se fazer um pedido ou desejo. Entretanto, há três desejos os quais não se podem fazer: o casamento, beleza e riqueza. Além disso, essa formação rochosa também pode lembrar o formato de um tamanduá ou um elefante. Na Cidade encontra-se o "Sítio do Camaleão", nome dado por conta de uma pintura que lembra tal animal. No local, existem, também, alguns pontinhos que lembram algarismos romanos, pode-se observar que no local havia pinturas mais nítidas, pois, tais não sofrem tanto com os raios do sol e com a chuva.

Outrossim, pode-se encontrar alguns sítios ao longo do trajeto, os quais são entendidos como as formações rochosas que contêm pinturas rupestres em sua estrutura. Nesse aspecto, são catalogados 26 (vinte e seis) sítios no PARNA, no entanto, apenas cinco são abertos para visitação, visto que os demais se encontram em uma área de reserva (ICMBio, 2020). Dessa forma, destaca-se um dos sítios, conhecido como o sítio da mão de seis dedos.

No PARNA não foi feito um estudo detalhado a respeito das pinturas encontradas na região, sendo realizada apenas uma sondagem por Conceição Lages, a qual usou o carbono 14, para dar a datação e ter o conhecimento acerca do material que foi usado para fazer as pinturas. Tendo isto, as pinturas encontradas do local têm entre 5 a 10 mil anos, 
e foi usado o dióxido para fazer o levantamento dos materiais utilizados nas pinturas, tendo sido encontradas: vegetais, argila e água, as quais misturadas tinha-se a tinta.

Esse sítio é o único que conta com uma mão de 6 (seis) dedos estampados na formação rochosa. Na parede, pode-se observar, também, pinturas de animais, pessoas, aves, pontos que provavelmente serviam para contagem, etc. Dentro da área possui duas tradições, as quais são as pinturas geométricas e pinturas agreste, que serviam como meio de comunicação dos povos que ali habitaram.

O PARNA também possui um pequeno sítio, conhecido como "Cartório", devido à grande quantidade de mãos estampadas na parede em três formatos que, segundo Conceição Lages, essa diferença servia para distinguir as tribos indígenas que foram os tabajaras, cariris, e os Tremembés, porém não há algo que comprove essa teoria. Nos sítios, tem-se claramente visível o problema do cupim, sendo necessária uma limpeza na estrutura da rocha, a qual é feita apenas por Conceição Lages, pois não é permitido usar qualquer tipo de material químico.

A condutora relatou sobre o recente incêndio que ocorreu no PARNA em 2008, pois nos meses de outubro, novembro e dezembro, a temperatura chega a 40 graus, e a vegetação fica seca e "toca uma na outra", o que ocasiona o incêndio, além dos moradores que residem perto do PARNA e fazem queimadas em suas roças, fato que pode afetar o PARNA. Após o incêndio foi contratado 12 brigadistas que ficam durante 6 meses fiscalizando e, quando algum morador próximo faz sua roça, eles ajudam para que não entre no parque. $\mathrm{O}$ incêndio danificou a vegetação e animais como o tamanduá, tucano, sagui, que ainda era possível ver no ano de 2007 segundo a condutora.

O outro sítio de pinturas rupestres, chama-se "A Pedra do Americano" e tem mais de 500 pinturas catalogadas. Recebe esse nome, pois na década de 1950 passaram dois norte-americanos que descobriram o sítio, então os mesmos tiraram o excesso de areia e o catalogaram. Passando-se algum tempo, o PARNA foi inaugurado e, por conseguinte, eles voltaram a fim de escavar mais, pois segundo os mesmos, ainda encontrariam mais pinturas, entretanto, não foi mais permitido, uma vez que, segundo os moradores, na primeira vez que escavaram, os mesmos levaram um pedaço de pintura para o seu país, porém sem alguma confirmação da veracidade desta informação.

Outro atrativo, além dos sítios, é a "Rocha da Jiboia" ou a "Biblioteca", formação na qual embaixo de sua "cabeça", assemelha-se a livros empilhados, a cavidade chamada 
pedra do descanso. Dessa forma, tal rocha serve de passagem para o mirante, passandose entre o "corpo da jiboia" para se ter acesso ao mesmo, na qual encontram-se degraus para a conexão até o topo do mirante. O mirante é o ponto mais alto com 50 metros de altura, 220 acima do nível do mar, e do seu topo se pode observar 70\% do PARNA, do mirante podem ser observadas as "cidades" $6,5,4$ e 3 .

$\mathrm{Na}$ entrada da "Terceira Cidade", por sua vez, pode-se ser encontrado outro sítio de pintura, o qual não está catalogado nos sítios de Conceição Lages, pois foram os próprios condutores do PARNA que descobriram ao abrir a trilha para diminuir a caminhada no sol escaldante do cerrado-caatinga. As pinturas são apenas pinturas em formato de traços. Além disso, uma outra formação do PARNA é a rocha que possui o formato semelhante aos três reis magos, sendo que o do meio se encontra de costas, e os outros dois de perfil, observando a rocha ao lado chamada pedra do segredo, a qual se assemelha a órgão sexual feminino. A seguir pôde observar a pedra de D. Pedro I, a qual se caracteriza com o imperador, devido à semelhança do perfil do mesmo.

Ao lado está a "Pedra do Dedo de Deus", pois há uma rocha em formato de coluna, assemelhando-se a um dedo e está sozinha apontando para o céu. Finalizando, por fim, a terceira cidade, tem-se a rocha que lembra um castelo, cujo furo em sua estrutura é onde acontece o solstício de inverno, no qual o sol nasce mais cedo e seus raios entram dentro do furo e vai crescendo no interior da rocha, até chegar ao outro lado, esse momento acontece apenas no dia 21 de junho.

Figura 4: A) Pedra da Tartaruga na Sexta Cidade e B) Gruta do Catirina na Quinta Cidade.

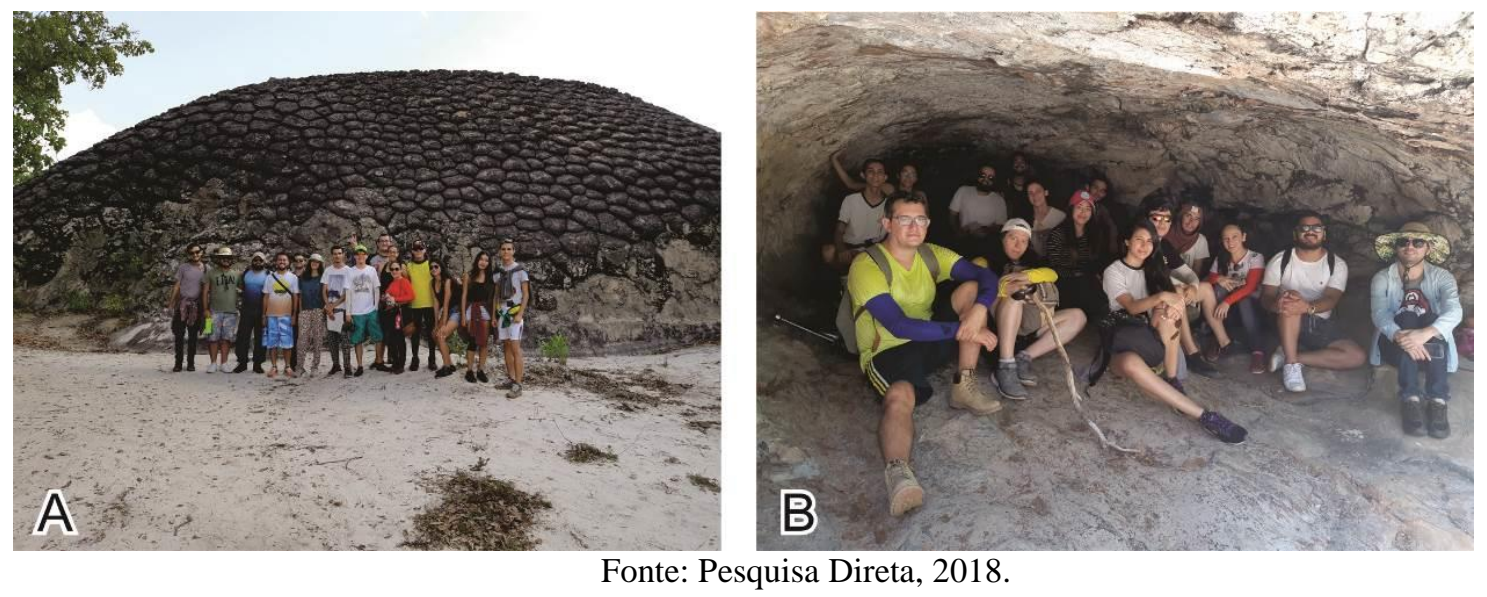

$\mathrm{Na}$ Quarta Cidade, tem-se o pequeno arco, que ao passar, de mesmo modo que o Arco do Triunfo, pode-se fazer um pedido. Ali, encontra-se a rocha no formato do mapa 
do Ceará, mais a frente temos o mapa do Brasil (Figura 5). Dando continuidade, tem-se a passagem do índio, cujo nome é devido ao fato de os moradores acreditarem que serviam para os índios, no entanto, também era usado para os moradores passarem e deixar a metade dos seus pecados. Dessa forma, ao passar, de acordo com o teste da fidelidade, não pode tocar na rocha. Ao lado temos o beijo dos lagartos, que segundo a guia, diz a lenda que quando eles se beijassem toda região viraria mar.

Figura 5: Formação com os contornos semelhantes ao mapa do Brasil, na Quarta Cidade e D) Arco do Triunfo, na Segunda Cidade.
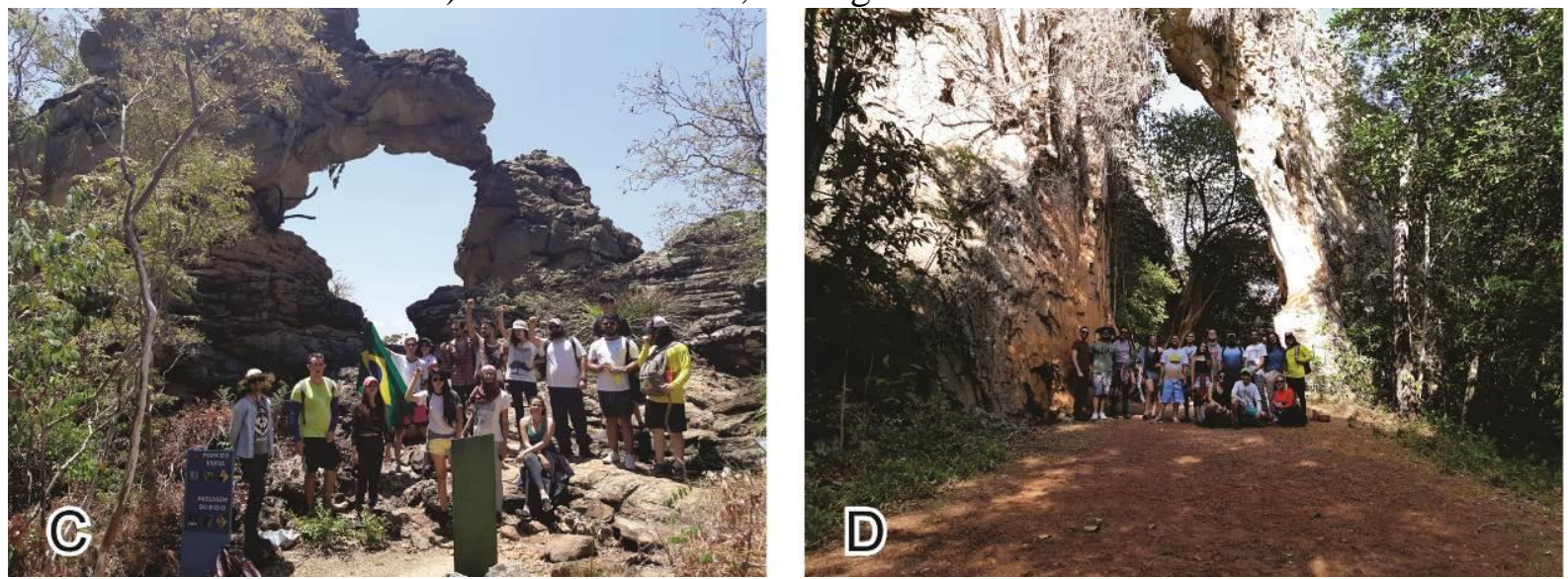

Fonte: Pesquisa Direta, 2018.

Na Quinta Cidade há a gruta do Catirina (Figura 6), um senhor rezador que chegou em 1931 com o seu filho, em busca da cura ou de esconder o seu filho Martinho Ferreira do Egito, pois o mesmo tinha epilepsia, doença que na época era considerada contagiosa e demoníaca. Os dois moraram na gruta por 13 anos até seu filho falecer com 52 anos no ano de 1944, enterrado ao lado da gruta. Catirina tinha desejo de ser enterrado ao lado do filho, porém, não foi realizado o que o mesmo desejava, pois ele saiu do local e ninguém soube do seu destino nem onde está enterrado. Na gruta contém um pilão, no qual ele fazia as ervas e pisava arroz.

Figura 6: E) Caminhada entre a Quarta e Quinta Cidades, F) Pintura rupestre e G) Cachoeira próxima à Primeira Cidade. 

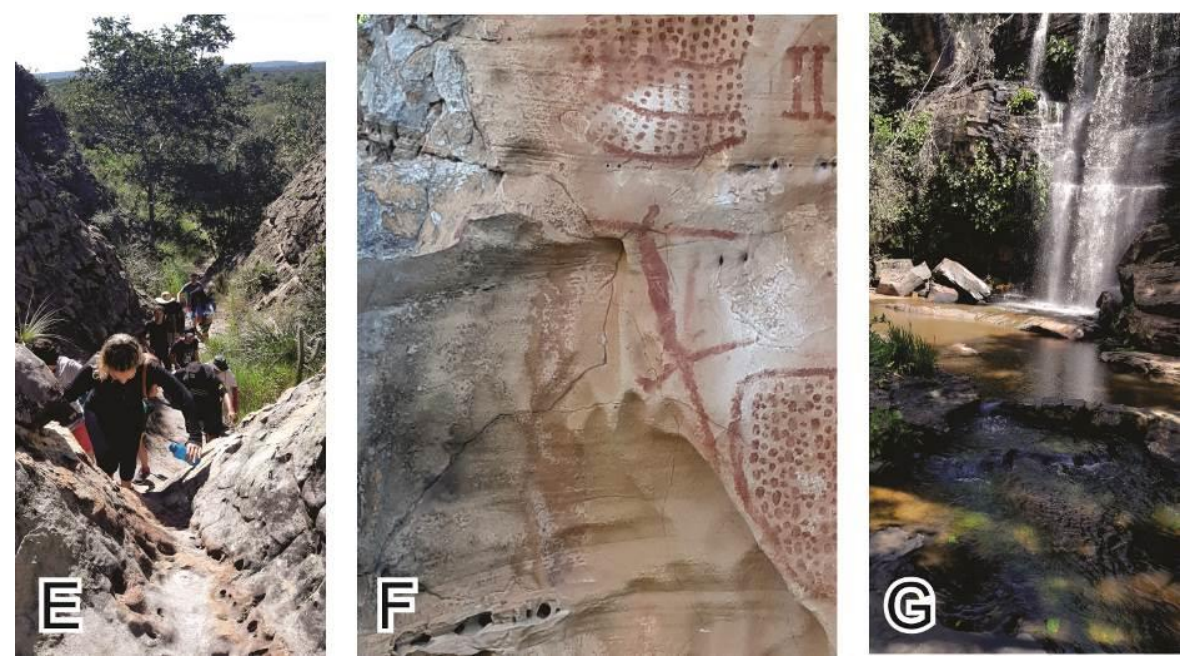

Fonte: Pesquisa Direta, 2018.

A sexta Cidade abriga a Pedra da Tartaruga (FIGURA 2), umas das formações mais famosas do PARNA. Também ficam ali a Pedra do Elefante, Pedra do Cachorro. Essa é a Cidade mais próxima do Centro de visitantes. Por fim, a Sétima Cidade se encontra no trajeto, podendo ser visitada por meio de carro ou ônibus, local no qual abriga uma rocha que se parece a um dragão chinês; e a gruta do pajé, local que contém pinturas rupestres nas paredes e no teto da rocha, identificados como pontinhos e riscos. Seguindo, por fim, para a última parada, a Cachoeira do Riachão, queda d'água bem presente devido às chuvas, tendo, portanto, encerrado o trajeto e as atividades guiadas.

\section{METODOLOGIA}

Para a realização da presente pesquisa, utilizou-se como método a pesquisa bibliográfica e documental por meio de leituras em livros, artigos, editais, documentos e legislação que tratam do tema referente a Unidades de Conservação, Parques Nacionais, etc. Nessa perspectiva, a pesquisa bibliográfica envolve “[...] toda bibliografia já tornada pública em relação ao tema de estudo, desde publicações avulsas, boletins, jornais, revistas, livros, pesquisas, monografias, teses, material cartográfico etc." (LAKATOS; MARCONI, p.166, 2010).

Além disso, o presente artigo trata-se de uma abordagem qualitativa e pesquisa de campo, por meio da visita ao PARNA nos dias 24, 25 e 26 de maio de 2019, foi analisada a estrutura do local e, posto isto, realizou-se a análise SWOT a partir dos dados colhidos durante a visita. Dessa forma, de acordo com Gil (2002) as análises qualitativas visam extrair a opinião dos indivíduos sobre as situações em que vivem, neste caso, sobre a vivência no PARNA de Sete Cidades. De acordo com Apolinário (2012), essa abordagem 
lida com fenômenos e prevê a análise hermenêutica das informações coletadas.

A pesquisa de campo, por outro lado, conforme discorre Lakatos e Marconi (2010, p.169) "consiste na observação de fatos e fenômenos tal como ocorrem espontaneamente na coleta de dados a eles referentes e no registro de variáveis que se presume relevantes para analisá-las”. Nesse sentido, após a realização da visita ao PARNA, foi possível coletar os dados e informações conforme os condutores falavam, sendo possível elaborar uma lista para a posterior análise SWOT. Posto isto, as informações serão organizadas com base na ferramenta de análise do ambiente interno e externo, conhecida por Análise SWOT, que busca analisar aspectos como força, fraqueza, ameaças e oportunidades (DORNELAS, 2011).

O termo SWOT é uma sigla oriunda das palavras em inglês Strengths (Forças - pontos fortes da instituição que podem ser potencializados); Weaknesses (Fraquezas - pontos fracos da instituição que devem ser minimizados ou supridos); Opportunities (Oportunidades - condições externas que podem, quando aproveitadas, influenciar positivamente o funcionamento da instituição) e; Threats (Ameaças - condições externas que podem, quando não minimizadas ou impedidas, influenciar negativamente o funcionamento da instituição), também conhecida em português como FOFA. (DE ARAÚJO; SCHWAMBORN, 2014, p.185)

Neste estudo, para a análise SWOT, baseou-se na análise dos pontos: administração do PARNA, os serviços turísticos oferecidos na área, os atrativos, sinalização, infraestrutura, etc. A análise de SWOT permite embasar gestores na tomada de decisões, direcionando suas ações para a correção de problemas adequando as capacidades internas com as possibilidades externas.

\footnotetext{
Esta matriz oferece direcionamento do planejamento estratégico, pois a partir das avaliações internas (forças e fraquezas) e do ambiente externo (oportunidades e ameaças), consegue-se observar pontos potenciais e vulneráveis, prever situações de neutralidades e sugere tendências positivas ou negativas, de acordo com cruzamento das informações indicadas pelas variáveis. (DE ARAÚJO; SCHWAMBORN, 2014, p. 186)
}

Tal análise será aplicada ao trabalho como forma de coleta de informações obtidas acerca do turismo no PARNA, sendo focados os pontos internos e externos do PNSC, a fim de detectar possíveis fraquezas, forças, oportunidades e ameaças. Diante do exposto, a análise SWOT buscará encontrar tais pontos para que se possa ter o conhecimento do que o PARNA oferece para o turismo ou como se trabalha tal atividade na área objeto de estudo.

\section{Análise SWOT Aplicada no PARNA}


A análise SWOT, conforme Araujo et al. (2013), surgiu a partir da década de 1960 por acadêmicos de Stanford Research Institute na administração, sendo uma ferramenta dentro do planejamento estratégico a qual analisa o ambiente interno e externo do local, a fim de auxiliar na tomada de decisões para atingir o objetivo final, desenvolvendo o turismo do destino.

O método de análise SWOT consiste numa metodologia utilizada para promover a análise de cenários, comumente utilizada em empresas. No entanto, esta técnica vem sendo aproveitada também como ferramenta para estabelecer o nível do desenvolvimento turístico em que se encontram as localidades, analisando os pontos fracos e fortes, as fraquezas e oportunidades destes locais. (DANTAS; MELO, 2008, p.118)

A caracterização ambiental interna é caracterizada pelos pontos fortes e fracos de dentro da organização do que pode ser feito para ser melhorado, dessa forma, faz-se necessário que saiba quais são as necessidades da organização e as principais causas dos seus pontos fortes e fracos. Já análise externa, compreende-se pelas oportunidades e ameaças do qual a organização não tem controle, desse modo, faz-se necessário que saiba quais são os objetivos almejados a longo prazo, conhecer os concorrentes e o público alvo, sendo alterações que devem ser feitas para o melhorar posicionamento no mercado. A partir do que foi observado pelos autores na pesquisa de campo realizada nos dias 24 , 25 e 26 de maio de 2019, observa-se no quadro 1 a análise $S W O T$ sugerida para o PARNA (QUADRO 1).

As forças envolvem a riqueza da biodiversidade sendo um grande diferencial incluindo os monumentos naturais, cachoeira e os sítios arqueológicos. A beleza cênica e o patrimônio natural e cultural são capazes de atrair turistas. Neste sentido, observa-se que a região possui uma infraestrutura de hospedagem e alimentação que pode ainda se desenvolver de acordo com o crescimento da demanda, porém já representa um suporte aos turistas que visitam o parque.

Os tipos de turismo realizados no parque são considerados forças, sendo estes o ecoturismo e o turismo científico visto que são práticas mais conscientes que buscam a preservação do meio ambiente e dos recursos naturais visitados. O cicloturismo também pode ser considerado uma força, pois corresponde a uma tipologia adicional de visitação ao parque.

Quadro 1: Forças e fraquezas da análise SWOT. 
Revista Tecnologia e Ambiente, v. 27, 2021, Criciúma, Santa Catarina/SC - ISSN Eletrônico 2358-9426 e ISSN Impresso 1413-8131

\begin{tabular}{|c|c|}
\hline FORÇAS & FRAQUEZAS \\
\hline Biodiversidade do local & Falta de divulgação do destino turístico \\
\hline Mudanças naturais de paisagem & Falta de acessibilidade \\
\hline Cicloturismo & Poucas lixeiras nas trilhas \\
\hline Instagram & Sinalização bilíngue \\
\hline Público ecoturista & Condutores não bilíngues \\
\hline Cachoeira & Não possui trabalho voltado para o \\
\hline Existência de hospedagem & Não possui Facebook oficial \\
\hline Presença de condutores & Pouca oferta para os visitantes \\
\cline { 1 - 1 } Sítios arqueológicos & Sinalização precária \\
\cline { 1 - 1 } Loja de souvenir & Falta de materiais didáticos \\
\cline { 1 - 2 } Turismo científico & \\
\cline { 1 - 2 } Monumentos naturais & \\
\hline
\end{tabular}

Fonte: Pesquisa direta, 2019.

A existência de condutores é importante para o local, pois torna a visitação segura e rica de conhecimento evitando problemas por parte dos visitantes como impactos ambientais e os orientam na locomoção no espaço. Além disto, há um espaço para venda de souvenires que incentiva a economia local, pois vende produtos de artesãos da região. O Instagram do parque é considerado um ponto forte visto que fornece informações atualizadas sobre o mesmo como localização e como chegar ao local, horários, atrativos, tipos de passeios e preços, entre outros. Após observar os pontos fracos e fortes presentes na análise interna do PARNA, o quadro 2 específica alguns aspectos da análise do que se encontra dentro do ambiente externo do parque, caracterizados como oportunidades e ameaças (Quadro 2).

Como pontos negativos foi observada a falta de divulgação do destino turístico atrelado a inexistência de um trabalho voltado ao marketing, ou seja, a comercialização sustentável do parque ao turismo. A prestação de informações em geral está prejudicada sendo esta traduzida em ausência de sinalização bilíngue, inexistência de Facebook, sinalização precária, condutores não bilíngues. Há ainda a carência de uma diversificação de atividades a serem oferecidas aos visitantes, assim como a falta de acessibilidade. Há 
ainda como ponto fraco poucas lixeiras nas trilhas.

Quadro 2: Oportunidades e ameaças da análise SWOT.

\begin{tabular}{|c|c|}
\hline OPORTUNIDADES & AMEAÇAS \\
\hline $\begin{array}{l}\text { Necessidade de fuga da rotina dos grandes } \\
\text { centros }\end{array}$ & Turismo de massa \\
\hline Proximidade da capital Teresina & Demanda sazonal \\
\hline $\begin{array}{c}\text { Gestão de marketing por meio de alunos do } \\
\text { curso de Turismo }\end{array}$ & \multirow{5}{*}{ Fragilidade do ecossistema } \\
\hline Comunidade atuando como condutor & \\
\hline $\begin{array}{l}\text { Voluntariado para auxiliar na gestão do } \\
\text { espaço }\end{array}$ & \\
\hline $\begin{array}{c}\text { Preocupação do poder público com o } \\
\text { desenvolvimento do turismo como fator de } \\
\text { influência econômica }\end{array}$ & \\
\hline Valorização Cultural & \\
\hline
\end{tabular}

As oportunidades são voltadas para uma demanda potencial que possui a necessidade de sair dos centros urbanos agitados e refugiar-se junto à natureza em momentos de lazer. Dentro desta realidade, a capital do Piauí, Teresina, fica próxima do parque que além de ser um destino emissor de turistas ao PARNA pode atuar como local com infraestrutura aeroportuária e rodoviária capaz de captar turistas de outras regiões interessado em visitar o parque.

O PARNA pode se beneficiar da mão de obra dos voluntários para a realização de atividades carentes de profissionais, podendo estes transmitir seus conhecimentos e deixar legados no local. A aproximação com a graduação em Turismo da Universidade Federal do Delta do Parnaíba pode trazer benefícios como a gestão do marketing do parque.

Ainda como oportunidades existem: a comunidade atuando como condutores, podendo inseri-la cada vez mais no processo de produção do turismo visando o benefício para a mesma; preocupação do poder público com o desenvolvimento do turismo como fator de influência econômica podendo atrair divisas para a melhoria da infraestrutura e gestão local; valorização cultural através do rico patrimônio cultural, sobretudo as inscrições rupestres que podem ser mais pesquisadas e divulgadas. 
As ameaças são voltadas para o turismo de massa que ao ser induzido pode causar impactos negativos no meio ambiente. A demanda sazonal pode trazer estabilidade econômica tanto para o parque como para os trabalhadores que sobrevivem do turismo. A fragilidade do ecossistema deve ser considerada ao criar ações de intensificação do turismo, pois se este é mal gerido pode causar danos irreversíveis. Assim, como posto dentro do quadro da análise SOWT realizada dentro do PARNA, é possível observar alguns pontos a serem melhorados para um maior benefício tanto do Parque como dos visitantes, podendo ser realizados a partir de estratégias.

\section{CONSIDERAÇÕES FINAIS}

Tendo em vista os aspectos observados e as informações adquiridas ao longo da visita ao PARNA, pôde-se observar que o mesmo, como um grande potencial turístico e um lugar que possui grande riqueza natural e um ecossistema variado, encontrados na interseção de dois biomas (cerrado e caatinga), além de diversos sítios com pinturas rupestres, apresentando como oportunidades variadas formas de se fazer o turismo, tais como o ecoturismo, turismo de aventura, turismo cultural, turismo científico, etc.

Não obstante, apesar dessa vasta riqueza, percebe-se uma fraqueza no que diz respeito à visitação e divulgação do Parque, pois nota-se que não há um serviço de marketing responsável pela sua divulgação. Ademais, percebe-se a falta de incentivo voltada para o turismo no local, enfocando aqui a presença de um Hotel e um Restaurante que estão desativados há dez anos, o que poderia ser uma oportunidade para o desenvolvimento do turismo no local.

Como uma UC de Proteção Integral, pôde-se notar que o PARNA de Sete Cidades está legalizado, sendo gerido pelo ICMBio e está seguindo as normas propostas pelo Sistema Nacional de Unidades de Conservação (SNUC), no que diz respeito às UC de Proteção Integral. Dessa forma, apresenta fundamental importância na proteção de espécies tanto de animais como vegetais da área de transição dos dois biomas, sendo necessário o controle de pessoas dentro do PARNA devido à fragilidade do ecossistema.

O programa voluntariado é de suma importância para esse controle e na ajuda da gestão do PARNA, podendo ser desenvolvidos incentivos voltados para o marketing e para o turismo, corroborando para o desenvolvimento da concepção do parque como um atrativo turístico. Observou-se, do mesmo modo, que os condutores são da região, o que 
é importante, pois possuem conhecimento acerca do lugar e identidade com a região.

Assim sendo, faz-se necessário que haja mais trabalhos voltados ao marketing do PARNA de Sete Cidades, visto que possui uma potencialidade turística considerável, fator que poderia fomentar de sobremaneira o turismo no PARNA e na região, explorando também os aspectos como sinalização, acessibilidade, capacitação dos condutores, etc. Diante do exposto, pode-se concluir que os objetivos da pesquisa foram alcançados na perspectiva do turismo e, a partir disso, espera-se obter um melhor desenvolvimento do Parque Nacional de Sete Cidades.

\section{REFERENCIAS}

APOLINÁRIO, Fabio. Metodologia da ciência: filosofia e prática da pesquisa. 2 ed. São Paulo: Cengage Learning, 2015.

ARAUJO, Luis César G. et al. Ações estratégicas: desafios e caminhos para a gestão contemporânea. São Paulo: Atlas, 2013. p. 120.

BOHRER, Claudio. DUTRA, Luiz. A Diversidade Biológica e o Ordenamento Territorial Brasileiro. In: ALMEIDA, Flávio. SOARES, Luiz (Org.). Ordenamento Territorial: Coletânea de textos com diferentes abordagens no contexto brasileiro. Rio de Janeiro: Bertrand Brasil, 2009. p. 117-147.

BRASIL, Ministério do Meio Ambiente. SNUC - Sistema Nacional de Unidades de Conservação da Natureza: Lei ${ }^{\circ}$ 9.985, de 18 de julho de 2000; Decreto $n^{\circ} 4.340$, de 22 de agosto de 2002; Decreto $\mathrm{n}^{\circ} 5.746$, de 5 de abril de 2006. Plano Estratégico Nacional de Âreas Protegidas: Decreto $n^{\circ}$ 5.758, de 13 de abril de 2006. Brasília: MMA, 2011. $76 \mathrm{p}$.

COUTINHO, Leopoldo. O Conceito de Bioma. Acta bot. bras, São Paulo, 14 jun. 2005. p. 13-23.

DANTAS, Nathallye Galvão de Souza. MELO, Rodrigo de Sousa. O método de análise SWOT como ferramenta para promover o diagnóstico turístico de um local: o caso do município de Itabaiana / PB. Caderno Virtual de Turismo, v.8, n.1, 2008. 118 p.

DE ARAÚJO, Marcelino Gomes; SCHWAMBORN, Silvia Helena Lima. A Educação Ambiental em análise SWOT. AMBIENTE \& EDUCAÇÃO-Revista de Educação Ambiental, v. 18, n. 2, p. 183-208, 2014.

DIEGUES, Antonio Carlos S. As áreas naturais protegidas, o turismo e as populações tradicionais. In: SERRANO, Célia M. Toledo; BRUHNS, Heloisa T. Viagens à Natureza: Turismo, Cultura e Ambiente. s/d. p. 85-102.

DORNELAS, José Carlos Assis. Plano de negócios: seu guia definitivo. $2^{\mathrm{a}}$ reimp. Rio de Janeiro: Elsevier, 2011.

GAUTHIER, Fernando Alvaro O.; RADOS, Gregório Jean Varvakis; TODESCO, José Leomar; SANTOS, Neri dos; SELIG, Paulo Maurício; PACHECO, Roberto Carlos dos Santos. Ações de Gestão do Conhecimento para o aprimoramento da Política 
Nacional de Turismo: Parques Nacionais. Universidade Federal de Santa Catarina UFSC: Departamento de Engenharia do Conhecimento - DEGC, 2014. p. 1-107.

GIL, Antônio Carlos. Como elaborar projetos de pesquisa. 4. ed. São Paulo: Atlas, 2002.

MARCONI, Marina. de Andrade,; LAKATOS, Eva Maria. Metodologia científica. 7. ed. São Paulo: Atlas, 2010.

RUSCHMANN, Doris van de Meene. Turismo e planejamento sustentável: A proteção do meio ambiente. Campinas, SP: Papirus, 1997. (Coleção Turismo)

SEBRAE. Caderno de atrativos turísticos. São Paulo. Disponível em: http://www.bibliotecas.sebrae.com.br/chronus/ARQUIVOS_CHRONUS/bds/bds.nsf/e6 ab735ac11e71802d2e44cbce6d63f4/\$File/SP_cadernodeatrativosturisticoscompleto.16. pdf.pdf. Acesso em: 12 de nov. 2017. 17 p.

SILVEIRA, Marcos Aurélio Tarlombani da. Geografia aplicada ao turismo: fundamentos teórico-práticos. Curitiba: InterSaberes, 2014.

SOUZA, A. F. S.; PEREIRA, S. M. F. AS QUEIMADAS NO PARQUE NACIONAL DE SETE CIDADES: uma ameaça para a conservação da biodiversidade. Revista SOMMA, v. 5, n. 1, p. 102-109, 2019.

PIRACURUCA WEB1. Mapa do Parque Nacional de Sete Cidades. Disponível em: http://piracurucaweb1.blogspot.com.br/p/cultura.html. Acesso em: 25 de mai. 2018.

VARELLA, L. S. S; NOVAIS, J. W. Z. Determinação da Condutividade Térmica do Solo em área de Pastagem no Cerrado Mato-Grossense. 2018. 